\title{
International Medical Electives: Another Victim to the COVID Pandemic
}

\author{
Jack Thundercliffe ${ }^{1}\left[\right.$ Megan Roberts $^{1}[$
}

Accepted: 4 November 2021 / Published online: 12 November 2021

(c) The Author(s) under exclusive licence to International Association of Medical Science Educators 2021

\section{To the Editor:}

We read the commentary "Student Doctors: Learning from the Front Line" with great interest and would like to expand on this, with emphasis on overseas medical electives: a front-line clinical experience the COVID pandemic has critically affected [1].

The medical elective has long been regarded as the highlight of medical school. Students experience the clinical environment in a foreign country, oftentimes in a profoundly different healthcare system and culture. This offers students first-hand experience of global health, an area neglected within the medical school curriculum, despite its importance in our increasingly connected world and as showcased by the pandemic [2]. Furthermore, as Checkley and colleagues discuss, typical medical school placements limit a student's team involvement and autonomy [1]. Electives may provide students more responsibility and experience within clinical environments.

Historically, most UK medical students undertook electives abroad [3]. The COVID pandemic has stolen this opportunity from a generation of medical students worldwide. Will their future clinical practice suffer as a consequence?

The UK's General Medical Council (GMC) states that graduates must "evaluate the determinants of health and disease and variations in healthcare delivery and medical practice from a global perspective and explain the impact that global changes may have on local health and wellbeing" [4]. However, there is variability in global health teaching and no standardised curriculum that all UK medical students cover [5]. Without international electives, a key opportunity to meet this outcome is lost.

Less developed nations are popular elective destinations [6]. Many medical students have taken up roles as vaccinators and clinical assistants in the UK - why not utilise them abroad to help roll out vaccines where they are needed most? As Checkley and colleagues mentioned, during the pandemic, medical students have felt more valued in working

Jack Thundercliffe

jthundercliffe@hotmail.co.uk

1 GKT School of Medical Education, King's College London, Guy's Campus, Great Maze Pond, London SE1 1UL, UK clinical roles. Furthermore, the great responsibility of these roles was also considered to increase students' readiness for practice [1]. This degree of responsibility could be offered in overseas electives.

Will the international elective return to its former glory as a rite-of-passage at the climax of undergraduate medical education, or will the uncertainty posed by virus variants and unpredictable travel restrictions continue to stand in the way? Given the correct precautions are taken with respect to vaccination, testing and PPE use, we must consider this an essential aspect of medical education and encourage frontline international electives once more.

\section{Declarations}

Ethics Approval NA

Informed Consent NA

Conflict of Interest The authors declare no competing interests.

\section{References}

1. Checkley EW, Prosser CJ, Sandler RD. Student doctors: learning from the front line. Med Sci Educ. 2021;31(4):1549-50.

2. Bandyopadhyay S, Thomas HS, Gurung B, Trout I, Wadanamby SW, Akhbari M, et al. Global health education in medical schools (GHEMS): a national, collaborative study of medical curricula. BMC Med Educ. 2020;20(1):389.

3. Miranda JJ, Yudkin JS, Willott C. International Health Electives: four years of experience. Travel Med Infect Dis. 2005;3(3):133-41.

4. Outcomes for graduates. [cited 2021 Sep 10]. Available from: https://www.gmc-uk.org/education/standards-guidance-and-curri cula/standards-and-outcomes/outcomes-for-graduates.

5. Matthews NR, Davies B, Ward H. Global health education in UK medical schools: a review of undergraduate university curricula. BMJ Glob Health. 2020;5(12):e002801.

6. Banerjee A. Medical electives: a chance for international health. J R Soc Med. 2010;103(1):6-8.

Publisher's Note Springer Nature remains neutral with regard to jurisdictional claims in published maps and institutional affiliations. 